\title{
PENINGKATAN PENGETAHUAN IBU BALITA MELALUI PENGENALAN PROGRAM KADARZI DI KELURAHAN WONOKUSUMO SURABAYA
}

\author{
Increasing Mother Knowledge Through KADARZI Program in Wonokusumo Surabaya \\ Riris Diana Rachmayanti \\ Departemen Promosi Kesehatan dan Ilmu Perilaku, Fakultas Kesehatan Masyarakat, Universitas Airlangga \\ E-mail: riris.diana@fkm.unair.ac.id
}

\begin{abstract}
ABSTRAK
Pelaksanaan program KADARZI belum maksimal dikarenakan banyaknya keluarga yang belum tahu dan belum memahami keberadaan program. Salah satu wilayah dengan pengetahuan yang rendah tentang program KADARZI adalah kelurahan Wonokusumo Surabaya. Tujuan penelitian ini adalah untuk mengetahui peningkatan pengetahuan ibu sesudah diberikan intervensi di Kelurahan Wonokusumo Surabaya serta mengidentifikasi faktor penyebab masalah gizi balita (predisposing, reinforcing dan enabling). Studi ini merupakan studi pra-eksperimental dengan rancangan one group pretest-posttest design. Penelitian dilakukan di RW 02 Kelurahan Wonokusumo, Januari-Februari 2017. Pengambilan data dilakukan secara kuantitatif dan kualitatif. Sebanyak 38 ibu yang memiliki anak balita dan hadir di posyandu di RW menjadi sampel dalam penelitian ini. Data kuantitatif meliputi pengetahuan dan sikap ibu sebelum dan sesudah intervensi. Uji statistik yang digunakan paired sample t-test. Metode kualitatif dikumpulkan melalui observasi dan in-depth interview kepada ketua RW 1 orang dan kader ( 8 orang). Intervensi berupa health education menggunakan media leaflet, video dan simulasi membuat modisco (sebagai salah satu cara untuk membuat dan mengolah bahan makanan lokal yang lebih bergizi). Waktu intervensi dilakukan 1 kali dengan durasi 4 jam. Hasil penelitian menunjukkan adanya peningkatan pengetahuan yang signifikan sebelum dan sesudah intervensi $(p=0,043)$. Nilai pengetahuan responden meningkat dari 47,9 menjadi 82,6. Identifikasi penyebab masalah gizi pada balita ada 3 faktor yaitu predisposing, reinforcing, enabling. Intervensi health education dapat meningkatkan pengetahuan ibu tentang pemenuhan gizi balita dan program KADARZI.
\end{abstract}

Kata kunci: gizi balita, KADARZI, pengetahuan, wonokusumo

\begin{abstract}
The implementation of the KADARZI program has not been maximized due to the many families who do not know and do not understand the existence of the program. One area with low knowledge about the KADARZI program is the Wonokusumo Surabaya district. The purpose of this study was to analyze the improvement of mother knowledge after given an intervention in the Wonokusumo Sub-district of Surabaya and to identify factors that causing nutrition problems of children under five (predisposing, reinforcing and enabling). This was a pre-experimental study with one group pretest-posttest design. The study was conducted in RW 02 Wonokusumo Village, January-February 2017. Data collection was carried out quantitative and qualitatively. A total of 38 mothers had children under five and present at the posyandu in $R W 2$ were sampled in this study. Mother knowledge before and after the intervention were collected qualitatively. Paired sample t-test was used to analyze the differences. The qualitative data were collected through observation and in-depth interview to the head of $R W 1$ person and cadre (8 people). Interventions of health education using leaflet, video and simulation of making modisco (as one way to create and process nutritious local food). Intervention was conducted one time during the Posyandu. Activities were held once with 4 hours duration. The results showed that the knowledge score was increased from 47.9 to 82.6 there was a significant increase in knowledge between before and after the intervention ( $p=0.043$ ). The causes of nutritional problems in children under five were 3 factors: predisposing, reinforcing, enabling. Health education interventions can improve maternal knowledge about the nutritional fulfillment of children under five and the KADARZI program
\end{abstract}

Keywords: nutrition of children under five, KADARZI, knowledge, wonokusumo

Riris D.R. MGI (2018) 176-182

DOI: 10.20473 /mgi.v13i2.176-182 


\section{PENDAHULUAN}

Berdasarkan data BPS Kota Surabaya tahun 2017 Kecamatan Semampir merupakan salah satu kecamatan miskin di wilayah Surabaya, hal ini karena pada Kecamatan Semampir banyak pendatang yang bermukim dan bukan penduduk tetap. Data penduduk musiman laki-laki sebanyak 1721 orang dan perempuan sebanyak 1513 orang. Wilayah Semampir terdiri dari 5 kelurahan yaitu Kelurahan Ampel, Kelurahan Pegirian, Kelurahan Sidotopo, Kelurahan Ujung dan kelurahan Wonokusumo. Salah satu wilayah yang menjadi tempat penelitian adalah di Kelurahan Wonokusumo tepatnya RW 2. Jumlah penduduk di RW 02 kurang lebih ada 4.517 jiwa dengan 1989 KK yang terbagi dari 12 RT. Sebagian besar wilayah RW 02 berada di daerah bantaran Sungai Jatipurwo. Berdasarkan data Kecamatan Semampir tahun 2017 mayoritas penduduk RW 02 bekerja sebagai pekerja swasta yang cenderung mempunyai penghasilan menengah ke bawah. Berat Badan yang berada di Bawah Garis Merah (BGM) pada KMS merupakan salah satu cara untuk menilai seseorang menderita gizi buruk, tetapi bukan berarti seseorang balita telah menderita gizi buruk, karena ada anak yang telah mempunyai pola pertumbuhan yang memang selalu dibawah garis merah pada KMS.

Berdasarkan hasil interview dengan bidan puskesmas Wonokusumo diperoleh bahwa salah satu faktor yang menyebabkan kasus gizi buruk di kelurahan Wonokusumo adalah adalah ketidakaktifan orang tua di kegiatan posyandu, kemiskinan karena banyak pendatang musiman, dan adanya penyakit bawaan atau penyakit penyerta yang dapat mengurangi berat badan balita. Berdasarkan data Puskesmas Wonokusumo tahun 2017 di wilayah Kecamatan Semampir masih ada balita yang berada dibawah garis merah. Cakupan pemberian PMT (Pemberian Makanan Tambahan) Pemulihan bagi balita gizi buruk mencapai 100\%. PMT Pemulihan diberikan dalam bentuk susu selama 90 hari berturut-turut. Selain itu di wilayah Wonokusumo pengetahuan masyarakat tentang program KADARZI masih rendah. Hanya 2 dari 10 orang yang tahu tentang program KADARZI.

Salah satu program untuk peningkatan status kesehatan bayi dan balita berbasis keluarga adalah program KADARZI. Keseriusan melaksanakan program perbaikan gizi menuju KADARZI ditetapkan dalam keputusan Menteri Kesehatan Republik Indonesia Nomor 747/MENKES/ SK/VI/2007 TANGGAL 21 Juni 2007 tentang Pedoman Operasional Keluarga Sadar Gizi di Desa Siaga. Menurut Depkes (2007) dalam pedoman KADARZI menyatakan bahwa Keluarga Sadar Gizi (KADARZI) adalah suatu keluarga yang mampu mengenal, mencegah dan mengatasi masalah gizi setiap anggotanya. Suatu keluarga disebut KADARZI apabila telah berperilaku gizi yang baik yang dicirikan minimal dengan: (a) Menimbang berat badan secara teratur, (b) Memberikan Air Susu Ibu (ASI) saja kepada bayi sejak lahir sampai umur enam bulan (ASI eksklusif), (c) Makan beraneka ragam, (d) Menggunakan garam beryodium, (e) Minum suplemen gizi sesuai anjuran.

Tujuan diselenggarakannya program Kadarzi, yaitu adalah agar keluarga dapat mengatasi masalah gizi setiap anggotanya (Depkes 2009). Perilaku orang tua terutama ibu memiliki peran yang sangat penting terhadap keadaan gizi anaknya (Sediaoetama 2006). Menurut penelitian Syafly (2011) bahwa semakin baik perilaku KADARZI keluarga semakin baik status gizi balitanya baik berdasarkan indikator berat badan menurut umur maupun tinggi badan menurut umur.

Berdasarkan hasil observasi sampai saat ini di kelurahan Wonokusumo masih banyak masyarakat yang belum tahu tentang KADARZI. Hasil indepth dengan kader saat studi awal dapat diketahui bahwa bukan hanya pengetahuan yang kurang tentang KADARZI, namun fasilitas pendukung (peralatan posyandu) dan faktor pendorong (ibu mertua atau orang tua) yang juga berpengaruh terhadap pemenuhan gizi bayi dan balita masih kurang. Tujuan penelitian ini adalah untuk mengetahui peningkatan pengetahuan ibu sesudah diberikan intervensi di kelurahan Wonokusumo Surabaya serta mengidentifikasi faktor penyebab masalah gizi balita di kelurahan Wonokusumo.

\section{METODE}

Studi ini merupakan studi pra-eksperimental dengan rancangan desain penelitian yang digunakan 
one group pre-test-post-test. Pelaksanaan penelitian di RW 02 Kelurahan Wonokusumo, Kecamatan Semampir, Kota Surabaya, pada bulan Januari-Februari 2017. Pada penelitian ini sampel merupakan total populasi dari posyandu di RW 02 yaitu sebanyak 38 ibu yang hadir pada saat intervensi berlangsung serta bersedia mengisi inform consent untuk terlibat dalam penelitian. Pengetahuan diukur dengan pertanyaan sebanyak 30 pertanyaan. Pengetahuan dikategorikan menjadi 3 yaitu baik (nilai $\geq 80$ ), cukup (nilai 60-79) dan kurang (nilai $\leq 59)$ (Notoatmojo, 2010). Analisis paired t-test digunakan untuk melihat perubahan pengetahuan tentang program KADARZI (sebelum dan sesudah diberikan perlakuan health education). Subyek diberikan perlakuan berupa health education tentang program KADARZI, gizi seimbang dan pemenuhan gizi pada balita menggunakan media leaflet, video dan simulasi membuat modisco. Modisco dipilih sebagai salah satu cara untuk membuat dan mengolah bahan makanan lokal yang lebih bergizi. Salah satu ciri keluarga KADARZI adalah memberikan makanan yang beragam. Modifikasi makanan dengan modisco. Menjadikan makanan tersebut lebih menarik dan mengandung lebih banyak energi karena terdapat kandungan susu atau mentega (dapat meningkatkan berat badan anak). Waktu pemberian intervensi health education dilakukan selama 1 kali pada saat posyandu berlangsung dengan durasi 4 jam. Adapun tahapan health education pertama pemberian leaflet tentang gizi seimbang dan pemenuhan gizi balita. Kedua, paparan dan diskusi tentang program KADARZI, gizi seimbang dan pemenuhan gizi pada balita dilakukan selama 1 jam 30 menit. Ketiga, pemutaran video terkait program KADARZI, gizi seimbang dan pemenuhan gizi pada balita selama 30 menit. Keempat, simulasi dengan melakukan pembuatan kolak pisang modisco untuk bayi dan balita. Bahan dasar mosidco (susu bubuk 100 gr, gula 5 gr, margarin 5 gr) dan bahan lokal yang digunakan adalah pisang kepok. Waktu pelaksanaan selama $2 \mathrm{jam}$. Pertanyaan pre-test dan post-test untuk melihat pengetahuan tentang program KADARZI dengan kuesioner sebanyak 30 pertanyaan. Identifikasi masalah gizi balita sesuai
Tabel 1. Karakteristik Responden

\begin{tabular}{lcc}
\hline \multicolumn{1}{c}{ Keterangan } & n & \% \\
\hline Umur & & \\
$\quad<20$ tahun & 18 & 47.4 \\
$21-30$ tahun & 13 & 34.2 \\
$\quad>30$ tahun & 7 & 18.4 \\
Tingkat Pendidikan & & \\
$\quad$ SD/ MI & & \\
SMP/ MTS & 11 & 28.9 \\
SMA/MA & 27 & 71.1 \\
PT & & \\
Pekerjaan & & \\
IRT & 15 & 39.5 \\
Berdagang & 17 & 44.7 \\
$\quad$ Karyawan & 5 & 13.2 \\
Suku & & \\
$\quad$ Madura & 33 & 86.8 \\
Jawa & 5 & 13.2 \\
\hline
\end{tabular}

dengan faktor budaya, faktor predisposing, faktor reinforcing dan faktor enabling menggunakan metode kualitatif dengan observasi dan in-depth interview kepada perangkat RW (ketua RW 1 orang) dan kader (sebanyak 8 orang).

\section{HASIL DAN PEMBAHASAN}

\section{Karakterisik Responden}

Berdasarkan tabel 1 sebagian ibu balita besar memiliki tingkat pendidikan yang rendah (SMA) dan mayoritas suku Madura. Baik pendatang dari Madura atau keturunan Madura.

Menurut penelitian Arbella (2013) tingkat pendidikan seseorang dapat menentukan cara berpikir orang tersebut. Hal ini dikarenakan responden yang berpendidikan tinggi cenderung memiliki wawasan yang lebih luas daripada responden yang berpendidikan rendah.

\section{Pengetahuan Ibu tentang Pemenuhan Gizi Balita}

Gambar 1 menjelaskan bahwa sebagian besar ibu di RW2 Kelurahan Wonokusumo memiliki pengetahuan yang kurang tentang pemenuhan gizi balita. Berdasarkan hasil kuesioner yang disebarkan pada pertanyaan tentang pemenuhan gizi. Sebagian besar ibu tidak memperhatikan umur balita dan jenis makanan yang diberikan. Sebagian besar ibu menyediakan makanan yang sama antara 
Tabel 2. Tingkat Pengetahuan Sebelum dan Setelah Penyuluhan KADARZI

\begin{tabular}{lcccc}
\hline \multirow{2}{*}{ Tingkat Pengetahuan } & \multicolumn{2}{c}{ Pre-test } & \multicolumn{2}{c}{ Post- test } \\
\cline { 2 - 5 } & $\mathbf{n}$ & $\mathbf{\%}$ & $\mathbf{n}$ & $\mathbf{\%}$ \\
\hline Kurang & 18 & 47,4 & 0 & 0,0 \\
Cukup & 20 & 52,6 & 3 & 7,9 \\
Baik & 0 & 0 & 35 & 92,1 \\
\hline \multicolumn{1}{c}{ Mean SD } & $47,9 \pm 8,5$ & $82,6 \pm 8,8$ \\
\hline \multicolumn{4}{c}{0 -value } & \multicolumn{3}{c}{0,043} \\
\hline
\end{tabular}

makanan balita dengan anggota keluarga lainnya. Sehingga dalam menolak makanan ibu balita tidak memperhatikan kebutuhan dan status gizi balita.

Sebelum penyuluhan, tingkat pengetahuan masuk dalam kategori responden cukup dan kurang, setelah intervensi health education pengetahuan responden meningkat $92,1 \%$ menjadi baik. Rata-rata nilai pengetahuan responden meningkat dari 47,9 menjadi 82,6 ( $p=0,043)$. Hasil ini menunjukkan adanya perbedaan yang signifikan antara pengetahuan ibu sebelum dan sesudah diberikan intervensi. Intervensi health education dengan memberikan informasi secara langsung, memberikan media berupa leaflet dan praktek langsung dengan membuat modisco dapat meningkatkan pengetahuan responden.

Menurut penelitian Ulya dan Ridwan (2011) terdapat hubungan bermakna antara pengetahuan ibu dengan perilaku KADARZI. Menurut penelitian Octaviani dan Margawati (2012), terdapat hubungan antara perilaku KADARZI dengan status gizi anak balita $(\mathrm{r}=0,444, \mathrm{p}=0,005)$. Hasil penelitian Setiyaningsih (2007) menyebutkan semakin tinggi pengetahuan responden tentang

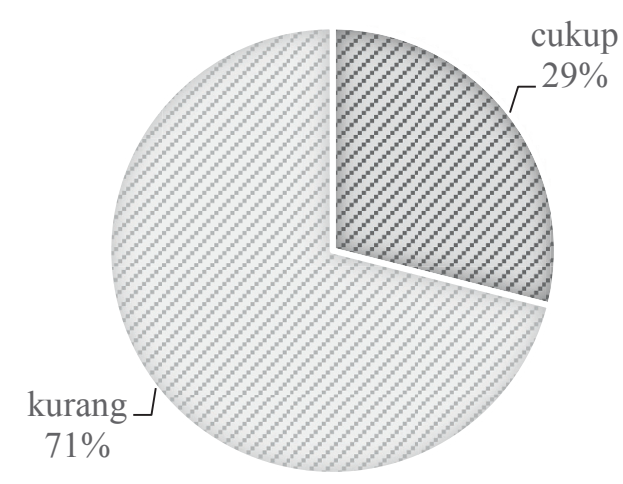

Gambar 1. Distribusi Pengetahuan Ibu tentang Pemenuhan Gizi Balita kurang
KADARZI maka akan semakin besar kemungkinan untuk melaksanakan KADARZI, sebaliknya semakin rendah pengetahuan responden tentang KADARZI maka akan semakin kecil kemungkinan untuk menerapkan KADARZI.

Penelitian Gabriel (2008) menyatakan bahwa terdapat korelasi yang positif dan nyata terdapat hubungan antara perilaku KADARZI dengan status gizi balita. Hal ini menunjukkan bahwa ketika keluarga melakukan atau menjalankan program KADARZI dengan baik, maka status gizi balita pada keluarga tersebut akan baik. Hal ini sesuai dengan tujuan diselenggarakannya program KADARZI, yaitu agar keluarga dapat mengatasi masalah gizi setiap anggota keluarganya. Perilaku ibu memiliki peran yang sangat penting terhadap keadaan gizi anaknya, terutama balita. Balita belum mampu untuk mengurus dirinya sendiri dengan baik (Sediaoetama, 2006). Oleh karena itu, perilaku gizi ibu yang baik sangat dibutuhkan untuk dapat mencegah serta mengatasi masalah gizi anak balitanya. Menurut Suhardjo (2003) pengetahuan tentang gizi dapat diperoleh melalui pengalaman, media massa, pengaruh kebudayaan atau pendidikan baik formal maupun non formal. Pengetahuan tentang gizi dipengaruhi oleh berbagai faktor, di antaranya faktor pendidikan, faktor lingkungan sosial serta frekuensi kontak dengan media massa.

Hasil penelitian Hariyadi dan Ekayanti (2011) menunjukkan bahwa rumah tangga dengan perilaku KADARZI yang kurang baik berpeluang untuk meningkatkan risiko kejadian stunting pada anak balita sebesar 1,22 kali lebih besar daripada rumah tangga dengan perilaku KADARZI yang baik. Hasil penelitian Denny (2013) menunjukkan bahwa ada hubungan yang bermakna antara pengetahuan keluarga dengan perilaku KADARZI. Studi Jayani (2015) menunjukkan ada hubungan antara kesadaran gizi keluarga dengan status gizi pada balita di Desa Sidoarjo Kecamatan Jambon Kabupaten Ponorogo.

Hasil penelitian yang telah dilakukan Arbella (2013), responden yang memiliki pengetahuan baik terkait KADARZI dikarenakan responden pernah mendapatkan informasi kesehatan khususnya mengenai KADARZI dari tenaga kesehatan. Pada penelitian ini responden belum 
pernah mendapatkan informasi sebelumnya dari tenaga kesehatan. Pada intervensi health education diberikan informasi tentang program KADARZI dan respons yang diberikan sangat baik sehingga terdapat peningkatan pengetahuan yang signifikan antara sebelum dan sesudah intervensi.

Penerapan teknologi juga dapat membantu meningkatkan pengetahuan. Sesuai dengan hasil penelitian Mardawati (2008) yang menyatakan bahwa penerapan informasi dan teknologi dapat meningkatkan pengetahuan ibu balita dan kader tentang keluarga sadar gizi. Pada penelitian ini penggunaan teknologi dan informasi dilakukan dengan mengombinasikan berbagai media seperti leaflet, paparan, video dan praktek langsung menggunakan modisco.

\section{KADARZI}

PERMENKES No. 23 tahun 2014 tentang Upaya Perbaikan Gizi menjelaskan tentang Program KADARZI. Pada program KADARZI, diberikan buku pedoman untuk pendampingan

keluarga agar dapat melaksanakan dan mengimplementasikan program dengan baik. Wujud perilaku KADARZI mencakup tingkat keluarga, masyarakat, pelayanan kesehatan dan pemerintah.

Depkes (2007) menyatakan pada tingkat keluarga harus memiliki pengetahuan dasar mengenai gizi dan memilih makanan secara tepat. Masalah yang menghambat penerapan perilaku KADARZI adalah adanya kepercayaan, adat kebiasaan dan mitos negatif pada keluarga. Sebagai contoh masih banyak keluarga yang mempunyai anggapan negatif dan pantangan terhadap beberapa jenis makanan yang justru sangat bermanfaat bagi asupan gizi.

Berdasarkan in-depth interview diketahui bahwa hambatan yang mungkin akan dihadapi dalam implementasi program adalah adanya penyampaian informasi tentang pelaksanaan, tujuan dan sasaran program yang kurang menyeluruh ditambah lagi dengan budaya setempat mengenai pemberian makanan pada bayi sebelum umur 6 bulan.

Menurut Depkes (2007) dalam buku pedoman pendampingan keluarga KADARZI menyatakan bahwa KADARZI merupakan suatu keluarga yang mampu mengenal, mencegah, dan mengatasi masalah gizi setiap anggota keluarganya. Hasil penelitian ini masih banyaknya pengetahuan ibu balita tentang gizi yang masih rendah, tidak tahu pemilihan bahan makanan yang bergizi, hal ini menunjukkan bahwa asuhan gizi di tingkat keluarga belum memadai.

\section{Faktor yang Memengaruhi Pemenuhan Gizi Balita}

Notoadmodjo (2005) mengatakan bahwa menganalisis perilaku manusia yang dimulai dari tingkat kesehatan. Kesehatan dipengaruhi oleh 2 faktor yaitu faktor perilaku (behavior causes) dan faktor diluar perilaku (non-behavior causes). Notoadmodjo (2003), menyatakan bahwa ada 3 faktor yang menentukan suatu perilaku, dalam hal ini perilaku yang dimaksud adalah pemenuhan gizi pada balita. 3 faktor tersebut yaitu predisposing, enabling dan reinforcing (Gambar 2).

\section{Identifikasi Predisposing Factor}

Notoadmodjo (2003) menyatakan bahwa predisposisi (predisposing factors), yaitu faktor-faktor yang mempermudah atau mempredisposisikan perilaku yang terwujud dalam pengetahuan, sikap, kepercayaan, keyakinan, nilai-nilai. Berdasarkan hasil faktor predisposing meliputi: pertama, rendahnya pengetahuan ibu mengenai pentingnya gizi untuk anak, ASI Ekslusif dan perilaku hidup bersih dan sehat (PHBS). Kedua, anggapan atau nilai pada orangtua bahwa gizi tidaklah penting, yang penting makanan itu mampu mengenyangkan perut. Ketiga Adanya adat kebiasaan dari mertua yang memberikan makanan pada bayi sebelum usia 6 bulan. Keempat ketidaksesuaian pemberian Makanan Pendamping

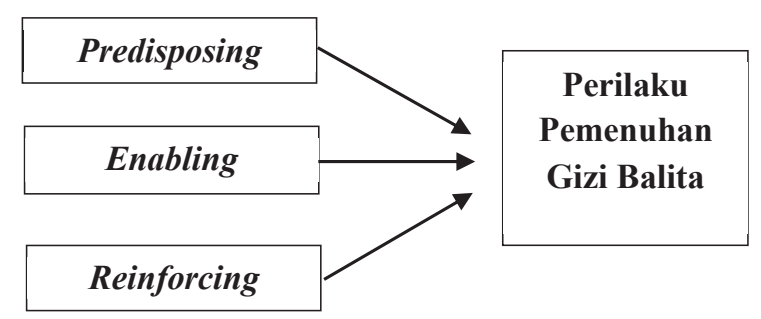

Gambar 2. Faktor Pemenuhan Gizi Balita di Kelurahan Wonokusumo 
ASI (MP-ASI) yang diberikan oleh kader dikarenakan pengetahuan yang masih rendah.

\section{Identifikasi Enabling Factor}

Notoadmodjo (2010), menyatakan bahwa faktor-faktor pendukung (enabling factors), yaitu faktor-faktor yang memungkinkan atau yang memfasilitasi perilaku atau tindakan. Pada penelitian ini, hasil identifikasi faktor enabling adalah jumlah kader sebanyak 8 orang, sebagian besar orang tua terutama ibu bekerja khususnya sebagai penjual sehingga waktu untuk mengurus anak relatif lebih sedikit, informasi yang diberikan sudah cukup banyak oleh puskesmas namun belum diimplementasikan dalam kehidupan sehari-hari karena alasan ekonomi (sebagai contoh: para ibu beranggapan bahwa konsumsi makanan seimbang berarti harus mengonsumsi daging, susu, dan makanan mahal lainnya). Kurangnya kemampuan memilih makanan yang beragam dapat membuat pengolahan makanan menjadi kurang bervariasi.

\section{Identifikasi Reinforcing Factor}

Pemerintah memiliki kebijakan mengenai pemberian MP-ASI sesuai usia anak, namun pada pelaksanaannya masih kurang karena penyebaran informasi yang belum menyeluruh. Dukungan ibu mertua untuk memberikan ASI ekslusif masih rendah. Faktor reinforcing atau penguat ibu mertua dan ibu kandung memiliki pengaruh yang kuat dalam pengambilan keputusan pada ibu balita. Ibu mertua atau ibu kandung sangat penting dalam menentukan perilaku pemenuhan gizi anak MP-ASI. Jika ibu kandung atau ibu mertua meminta atau memberi perintah untuk memberikan MP-ASI sebelum usia 6 bulan (biasanya diberikan pada usia 1 bulan atau 2 minggu) maka ibu balita akan mengikuti tanpa bisa menolak. MP-ASI yang diberikan berupa bubur, pisang, nasi ulet (nasi di haluskan dan dicampur pisang).

\section{Faktor Budaya}

Hasil identifikasi masalah gizi balita ditinjau dari aspek budaya diperoleh hasil bahwa budaya masih sangat kuat memengaruhi pola pemenuhan gizi balita. Sebagian besar masyarakat di kelurahan Wonokusumo berasal dari Madura. Budaya Madura beranggapan bahwa agar anak kuat maka diberi makanan yang cukup selain itu agar anak juga menjadi cepat besar.

Budaya nasi pisang masih terasa melekat pada warga RW 02 Kelurahan Wonokusumo, banyak bayi yang tidak mendapatkan ASI Eksklusif, dan pada umur 1 bulan atau bahkan ada yang 2 minggu bayi sudah diberikan nasi pisang.

Anggapan lain terkait MP-ASI dini adalah bayi belum kenyang karena belum makan sehingga mereka sering menangis. Hal tersebut terjadi karena didukung dengan kondisi pengetahuan ibu balita yang kurang mengenai gizi balita.

" dikasih nasi, makanan biar cepat besar mbak"

(XX, 22th)

"nasi diulet itu pas umur 1 bulan, pisang juga, kalau lapar nanti nangis terus...itu anak nangis itu lesu (lapar) mbak"

(NY, 29th)

" 2 bulan dikasih pisang kerok, itu ibu yang kasih biar tidak nangis"

(DN, 19th)

\section{KESIMPULAN DAN SARAN}

Intervensi berupa health education yang berisi informasi mengenai program KADARZI, gizi seimbang dan pemenuhan gizi pada balita menggunakan media leaflet, video dan simulasi membuat modisco dapat meningkatkan pengetahuan ibu. Hendaknya pemberian informasi tentang KADARZI dilakukan secara berkelanjutan serta ada evaluasi terhadap keluarga yang melaksanakan KADARZI. Kader dan tenaga kesehatan dapat memberikan informasi dan pendampingan terhadap keluarga yang memiliki balita secara berkesinambungan.

\section{DAFTAR PUSTAKA}

Arbella, V.M. (2013). Hubungan pengetahuan dan sikap ibu tentang keluarga sadar gizi dengan perilaku sadar gizi keluarga balita di Desa Karangsono Kecamatan Kwadungan Kabupaten Ngawi tahun 2013. Jurnal Kebidanan 2(5), $47-56$. 
BPS. (2017). Data sosial Surabaya. https:// surabayakota.bps.go.id/.

Depkes. (2007). Pedoman strategi keluarga sadar gizi (KADARZI). Departemen Kesehatan Direktorat Jenderal Bina Kesehatan Masyarakat Direktorat Bina Gizi Masyarakat.

Depkes. (2007). Pedoman pendampingan keluarga mепији KADARZI. Departemen Kesehatan Direktorat Jendral Bina Kesehatan Masyarakat Direktorat Bina Gizi Masyarakat.

Departemen Kesehatan RI. (2009). Buku paket pelatihan kader kesehatan dan tokoh masyarakat dalam pengembangan desa siaga. Jakarta: Pusat Promosi Kesehatan, Departemen Kesehatan RI.

Gabriel, A. (2008). Perilaku keluarga sadar gizi (KADARZI) serta hidup bersih dan sehat ibu kaitannya dengan status gizi dan kesehatan balita di Desa Cikarawang Bogor. (Skripsi yang tidak dipublikasikan) Institut Pertanian Bogor, Bogor.

Hariyadi, D., \& Ekayati, I. (2011). Analisis pengaruh perilaku keluarga sadar gizi terhadap stunting di Propinsi Kalimantan Barat. Jurnal Teknologi dan Kejuruan, 34(1), 71-80.

Jayani, I. (2015). Hubungan kesadaran gizi keluarga dengan status gizi pada balita di Desa Sidoarjo Kecamatan Jambon Kabupaten Ponorogo. Jurnal Care 3(3), 45-54.

Keputusan Menteri Kesehatan RI. Nomor 747/ MENKES/SK/VI/2007.

Mardawati. (2008). Upaya perbaikan gizi balita melalui gerakan keluarga sadar gizi (KADARZI) di RW 01 Kelurahan Gurun Laweh Kecamatan Nanggalo Padang. Warta Pengabdian Andalas 14(21), 196-201.

Notoatmodjo, S. (2010). Ilmu perilaku kesehatan. Jakarta: Rineka Cipta.
Notoadmodjo, S. (2005). Teori dan aplikasi promosi kesehatan. Jakarta: Rineka Cipta.

Notoatmodjo, S. (2010). Metodologi penelitian kesehatan. Jakarta: Rineka Cipta.

Octaviani, I., \& Margawati, A. (2012). Hubungan pengetahuan dan perilaku ibu buruh pabrik tentang KADARZI (keluarga sadar gizi) dengan status gizi anak balita (studi di Kelurahan Pagersari, Ungaran). Journal of Nutrition College. 1(1), 46-54.

Peraturan BPS No 37 Tahun 2010 tentang Klasifikasi perkotaan dan pedesaan.

PERMENKES tahun 2014 No 23 tentang Upaya perbaikan gizi.

Sediaoetama. (2006). Ilmu gizi. Jakarta: Dian Rakyat.

Septian, D. (2013). Pengetahuan dan sikap keluarga dengan perilaku keluarga sadar gizi (KADARZI). Jurnal Keperawatan. 9(1), 49-56.

Setiyaningsih, D. (2007). Hubungan antara pengetahuan dan sikap ibu tentang keluarga mandiri sadar gizi (KADARZI) dengan status KADARZI pada keluarga anak usia 5-59 bulan di puskesmas moyudan kabupaten sleman. (skripsi yang tidak dipublikasikan) Universitas Gajah Mada, Yogyakarta.

Suhardjo. (2003). Berbagai cara pendidikan gizi. PT Bumi Aksara, Jakarta.

Syafly, H. (2011). Hubungan Perilaku Keluarga Sadar Gizi (Kadarzi) Dengan Status Gizi Balita Di Kota Jambi. (skripsi yang tidak dipublikasikan) Institut Pertanian Bogor, Bogor.

Ulya, Z., \& Ridwan, I. (2011). Hubungan pengetahuan dan sikap ibu dengan perilaku keluarga sadar gizi (KADARZI) di Kelurahan Gunung Sari Bandar Lampung tahun 2011. Jurnal Kesehatan "Metro Sai Wawai" 4(1), 45-52. 